\title{
The African elephant: conservation and CITES
}

\author{
Robin Sharp
}

Human beings have been making (and almost certainly trading in) ivory artefacts for some 10,000 years. Yet it is only 8 years since the Parties to the Convention on International Trade in Endangered Species (CITES) placed a complete ban on international trade in elephant products by listing the African elephant

Loxodonta africana on Appendix I at Lausanne in 1989. Nevertheless, at the 10th Conference of the Parties to CITES in Harare this coming June, the listing will be challenged again by three of the Southern African countries who originally opposed it. This article describes what has happened on the ground since 1989, the political developments, examines the downlisting proposals, and looks at possible ways forward in the short-and medium-term. The views expressed are personal to the author.

\section{Effect of the CITES ban}

Some people view the ban on international commercial trade in ivory as an outstanding success: poaching has declined dramatically; elephant numbers are increasing. In truth, the facts are more complex or, in some cases, nonexistent. The African Elephant Specialist Group of IUCN (AfESG) recognizes 37 African countries as range states, while two more hold significant stocks of ivory. The will and competence of the governments of these countries to collect regular and reliable data on elephants and ivory varies enormously and there are many information gaps.

Although much pioneering work was done by those who produced the original African Elephant Database (see Douglas-Hamilton et al., 1992) in the late 1980s, the AfESG, which has since taken it over, has said 'Most information on elephant numbers on the continent has been guesswork and has not formed a suitable basis from which to determine population trends over time, or to discern the effects of policy or management' (Said et al., 1995). This means that the figure of 1.3 million elephants, hitherto accepted as the continental population at the start of the 1980 s, cannot be substantiated and thus the extent of the

(C) $1997 \mathrm{FFI}$, Oryx, 31 (2), 111-119 decline during the decade is not measurable. What can be said is that, before the ban, some countries saw dramatic declines due to poaching-e.g. Kenya, Tanzania and Zambiaothers experienced similar losses due to a combination of war and poaching-e.g. Angola, Mozambique, Sudan and Uganda - while others suffering neither disadvantage had stable or increasing numbers-e.g. Botswana, South Africa and Zimbabwe. For other countries e.g. Cameroon, Congo, Gabon and Zairethere is no reliable information about pre-ban trends, although significant declines due to poaching are highly probable. Because no one can go back to count elephant numbers in 1990 in cases where the data are missing or unreliable, we shall have to accept that there can never be a proper measure at a continental level of changes in population from the time when the trade ban came into effect. It follows that there can be no continental assessment of the contribution the ban may have made to reversing the overall decline, if indeed there has been a reversal.

What is possible is to establish recent and current numbers as the basis for measuring trends in particular countries, or specific populations in these countries, in the future. In setting out the current position the AfESG 
has classified the data into four categories of descending reliability: 'definite', 'probable', 'possible' and 'speculative' (Said et al., 1995). Using these categories the AfESG gives estimated continental totals from data available in 1995, which range from 286,234 for 'definite' to 579,532 , which covers all four categories. The new AfESG information also permits a regional overview and some useful comparisons of range states with the largest elephant populations. Table 1 shows the stark contrast at regional level between West Africa, with its tiny numbers, and the three other regions. It also highlights the continuing importance of the Central African range states, which, for a variety of reasons have been much less vocal in the CITES debate than East and Southern African countries and less able to furnish reliable data. It is perhaps even more striking to note that five of the 37 range states may hold more than two-thirds of the continental population of Loxodonta africana.

Once the ban on international ivory trade came into force, there should in theory have been a regular accumulation of ivory in all range states that did not set out to destroy it. TRAFFIC has made painstaking efforts to elicit information on stocks from the relevant governmental authorities and its latest assessment was presented at a meeting of the elephant range states in Dakar, Senegal (Milliken, in press). The figures were revised during the course of the meeting using information from government officials present (Table 2).

The regional totals for ivory stocks (which include public and registered private stocks) are interesting in their own right and particularly so when set alongside the population figures in Table 1. While the small quantity of ivory in West Africa is consistent with the small elephant population in the 13 range states, there is a major problem with the finding that the seven Central African countries hold 38 per cent of the estimated continental elephant population but only 5 per cent of the acknowledged ivory stocks. The high stock figures for the Southern region are no surprise, but it is noteworthy that Botswana and Zimbabwe, with their large elephant populations, should have ivory stocks that are much smaller than those of South Africa, with 10,000 elephants, and Namibia, with 7800. The stocks in Burundi and Sudan are essentially what the two countries held when the ban

Table 1. Selected African elephant population estimates

\begin{tabular}{|c|c|c|c|c|c|c|}
\hline $\begin{array}{l}\text { 1. Regions } \\
\text { (no. range states) }\end{array}$ & $\begin{array}{l}\text { Definite } \\
\text { number }\end{array}$ & $\begin{array}{l}\text { Probable } \\
\text { number }\end{array}$ & $\begin{array}{l}\text { Possible } \\
\text { number }\end{array}$ & $\begin{array}{l}\text { Speculative } \\
\text { number }\end{array}$ & Total & $\%$ total \\
\hline Central (7) & 7,320 & 81,657 & 128,648 & 7,594 & 225,219 & 37.77 \\
\hline Eastern (8) & 90,482 & 16,707 & 19,999 & 1,084 & 128,272 & 21.51 \\
\hline Southern (9) & 170,837 & 16,402 & 18,983 & 21,825 & 228,047 & 38.25 \\
\hline West (13) & 2,760 & 1,376 & 5,035 & 5,554 & 14,725 & 2.47 \\
\hline Continental total ${ }^{*}$ & $286,234^{*}$ & $101,297^{*}$ & $155,944^{*}$ & $36,057^{*}$ & $579,532^{*}$ & \\
\hline \multicolumn{7}{|l|}{ 2. Countriest (Region) } \\
\hline Tanzania (Eastern) & 73,459 & 12,419 & 12,301 & 0 & 98,179 & \\
\hline Zaire (Central) & 4,470 & 13,174 & 65,974 & 0 & 83,618 & \\
\hline Gabon (Central) & 0 & 61,794 & 20,218 & 0 & 82,012 & \\
\hline Zimbabwe (Southern) & 56,297 & 11,674 & 13,884 & 0 & 81,855 & \\
\hline Botswana (Southern) & 62,998 & 8,588 & 8,588 & 0 & 80,174 & \\
\hline Total & 197,224 & 107,649 & 120,965 & 0 & 425,838 & \\
\hline
\end{tabular}

\footnotetext{
* These numbers are not the sums of the regional totals because some figures derive from statistical uncertainty.

† Those with largest estimated populations.

Source: Said et al. (1995).
} 
came into force. Only in certain East and Southern African countries are ivory stocks reported to be growing annually in significant quantities, from which the only reasonable conclusion is that elsewhere new ivory from elephants being killed legally or illegally, or dying naturally, is finding its way into private hands and thence into the illegal international trade or into storage. It seems unlikely that a commodity that has been valued for so many generations is simply being left in the bush. Where stocks are growing but cannot be traded, storage facilities need to be upgraded and expanded at considerable expense: there is already evidence from Sudan and Djbouti that ivory held for too long in arid conditions loses weight and quality (Milliken, in press). While the destruction of stockpiles by Kenya and Zambia is a matter of public record, other range states with substantial numbers of elephants but static or non-existent stocks might be asked to address the question, 'Where has all the ivory gone?'

The one variable that might throw a direct light on the success or otherwise of the trade ban relates to 'before' and 'after' levels of poaching. Unfortunately, few range states

Table 2. African elephant ivory stocks in Africa 1996

\begin{tabular}{lrc}
\hline $\begin{array}{l}\text { 1. Regions } \\
\text { (no. countries) }\end{array}$ & Tonnes & \% of total \\
\hline Central (7) & 23 & 5 \\
Eastern (8) & 132 & 29 \\
Southern (9) & 213 & 46 \\
West (13) & 6 & 1 \\
Non-range (2) & 88 & 19 \\
Total & 462 & 100 \\
& & \\
2. Countries* (Region) & & \\
\hline South Africa (Southern) & 89 & 19 \\
Burundi (Non-range) & 86 & 19 \\
Tanzania (East) & 71 & 15 \\
Namibia (Southern) & 51 & 11 \\
Sudan (East) & 47 & 11 \\
Botswana (Southern) & 30 & 6.5 \\
Zimbabwe (Southern) & 29 & 6.5 \\
Total & 403 & 87 \\
\hline
\end{tabular}

* Those with largest recorded stocks.

Source: Milliken (in press). record this information comprehensively, although among countries that suffered heavily from poaching in the 1980s, Kenya is now recording all illegal killings, distinguishing between poaching and control incidents, while Tanzania has some precise data for certain protected areas (Dublin et al., 1995). The picture that emerges from these fragmentary records is of a dramatic decline in poaching following the ban but a gradual rise in the second biennium post-ban. Both the steep decline and the slight upward movement are considered to be partly due to variations in enforcement effort, which was generally much enhanced in 1989-90 and has fallen away since because of budget cuts. There is also widespread testimony from questionnaire surveys and orally from directors of wildlife that poaching is widespread and continuing in the majority of range states with large elephant populations, even if it cannot be quantified.

The final statistic relevant to an assessment of the effectiveness of the trade ban is the extent of the continuing illegal trade. Inferences can be made from seizures of illegal ivory but it is impossible to determine the total volume of illegal trade from such information. Data on seizures, mostly from official sources, have been assembled by TRAFFIC for the years 1989 onwards in the Bad Ivory Database System (BIDS). Records come from around the world, although, curiously, there is none from West Africa, where ivory markets are visible and must in most cases be using imported tusks. They also come in rather slowly, so that there is still important material to be

Table 3. Number and volume of reported ivory seizures 1989-93

\begin{tabular}{lcc}
\hline Year & No. seizures & Tonnes \\
\hline 1989 & 111 & 14.6 \\
1990 & 809 & 10.3 \\
1991 & 701 & 9.8 \\
1992 & 843 & 10.2 \\
1993 & 587 & 10.2 \\
Total & 3051 & 55.1 \\
\hline
\end{tabular}

Source: Adapted from Milliken and Sangalakula (1996). 
assembled for 1994 and only very partial information received for 1995 and 1996. The data available at November 1996 were presented at the Senegal meeting (Milliken and Sangalakula, 1996). From 1989 to date BIDS has recorded 3584 seizures contained an estimated 69 tonnes of ivory, of which 82 per cent comprised tusks or pieces of raw ivory, 7 per cent semi-worked blocks and 11 per cent worked pieces. Table 3 compares the summary data for 1989-93, for which BIDS data are most complete.

A fuller breakdown of these figures is given in Milliken and Sangalakula (1996), which shows that the most marked trend within the types of seizure is that in 1989 about twice the volume of tusks and other raw ivory was seized than in the following years, while the volume of worked ivory in subsequent years was $10-20$ times greater than in 1989 . There is no discernible trend in the figures for seizures of semi-worked blocks during these years, except that in 1989 and 1990 they exceeded the volume of worked ivory pieces, whereas the reverse was the case for 1991-93. Nevertheless, TRAFFIC has evidence of a 'cottage industry' producing semi-worked blocks of ivory for the Far-East name-seal market in no fewer than 14 African countries, compared with only two identified by the Ivory Trade Review Group (Cobb, 1989).

It appears that Zimbabwe was added to this list in the light of the leaked findings of the CITES Panel of Experts examining the country's draft elephant downlisting application for the 10th Conference of the Parties (The Times, London, 29 November 1996). It is also likely that when complete returns are available to BIDS the volume of seizures for 1994 will be higher than for the preceding 4 years, but that in itself will not substantiate the belief that there is an upward trend. Only the full data for 1995 and 1996 can establish or refute this. However, if the published Panel report confirms the leaked claim that Zimbabwean dealers were issuing permits for 'raw, semi-worked and finished ivory for commercial shipments to Japan, China, Thailand, Hong Kong, the Philippines, Indonesia, the United States and South Africa', it will be difficult to resist the contention that the illegal trade is growing in range and significance. The relative ease with which ivory can be seen being carved and on display for sale in West African countries, irrespective of whether their laws permit domestic trade, is another factor confirming the illegal international trade, because most of this ivory will be imported raw and exported as tourist souvenirs. Finally, reports from Tanzania, where over 6 tonnes of ivory were seized in 1966, offer further evidence of increased illegal trading.

It will be clear from the previous paragraphs that there is a great deal of uncertainty about elephant population numbers and trends since 1989, and even less information about poaching and the illegal ivory trade, while data on stockpiles indicate both problems and unanswered questions. It is safe to say that in some protected areas where poaching was heavy in the 1980s, the trade ban in conjunction with increased enforcement has aided the recovery of severely reduced populations, as has the ending of some ferocious civil conflicts, but for the majority of range states there is no means of knowing what effect the ban has had. It is incontrovertible that poaching and other illegal killing of elephants continues and represents a serious problem for under-resourced wildlife authorities. The illegal trade is widespread and serves both the Far Eastern market and the western tourist market more generally, although whether its volume is growing can only be guessed at this stage.

\section{The politics of the CITES ban}

Committed conservationists often deplore the fact that politics influences decisions of the CITES Parties on the listing of species, as if there were a purer way of dealing with problems. However, CITES is an international trade instrument created by governments as an act of policy for which they are accountable to their electorates or power base. Politics are therefore unavoidable and we neglect them at our peril. The objective should be to ensure that political decisions are rational, take 
account of sound science, and use public and private resources to the best effect.

It is therefore salutary to recall the circumstances of the ban and attempts to modify it since 1989 in order to see whether an outcome is possible that produces less ill-feeling and misunderstanding between the Parties. While most are aware that the debate at Lausanne was impassioned and a large majority (79 to 11) favoured Appendix I listing, it is often forgotten that inclusion of the 'Somali amendment' was crucial to the result. The latter allows a Party to apply for its elephant population to be downlisted to Appendix II if it can meet a number of criteria relating to conservation status, management, law enforcement and rigour in operating any resumed trade. The Conference decision, 7.9, also provided for an independent Panel of Experts appointed by CITES to prepare a report on these points to be considered along with each application. The Southern African countries with healthy elephant populations left Lausanne with the reasonable expectation that they could come to the next Conference with proposals that would satisfy the downlisting criteria and thus receive a fair, if not favourable, hearing. Nevertheless, 'reservations' against the listing among the range states were entered by Botswana, Malawi. South Africa, Zambia and Zimbabwe, while Namibia took the same position when it joined CITES in 1991. A reservation on an Appendix I listing allows a Party to trade in the species concerned with a non-Party or another Party holding a reservation, but there has been no legal trade in elephant products under this provision.

\section{Kyoto 1992}

There was therefore no surprise when South Africa, on its own, and the other five countries, jointly, submitted downlisting applications for consideration at the 8th Conference of the Parties, which took place in Kyoto in March 1992. The five latter countries had by then formed an agreement with the title Southern African Centre for Ivory
Marketing (SACIM) and their proposal envisaged a common registration and ivory marking system with a focal point in Botswana. Following a change of government and a change of policy, Zambia withdrew from the proposal and from SACIM membership just before Kyoto.

Regrettably, the searching reports of the appointed Panels on the downlisting applications were not available to delegates before they arrived in Kyoto, thus frustrating the good intention that they should influence the decisions of the Parties on the basis of science rather than emotion. Most government delegations have to prepare their positions in advance, especially on topics that give rise to domestic concern and lobbying; for example the UK approach was to try to find some comfort for the countries who had managed their elephants successfully but not to support downlisting*. As the Conference progressed the SACIM group offered to modify its proposal by holding back from trade until a secure system was in place, but it was too late. By then the European Community countries had heard a parade of African range state delegations asserting in simple but moving terms that they wanted the Appendix I listing to stay in place in order to discourage what they believed would be a widespread resumption of poaching. Although it became clear that the vote could not be won, SACIM and South Africa opted for a debate on the floor of the Conference, which deepened wounds without pointing a way forward. By the time they withdrew, considerable damage was done and the SACIM ministers held a press conference indicating that they were considering withdrawal from CITES and the resumption of the ivory trade. It was a bleak moment for the international conservation movement.

Because the elephant/ivory issue remains formally exactly where it was in 1992, some reflection on how Kyoto might have been better managed is perhaps in order. The proponents of change were anxious to establish that those who opposed them were shifting the

* The author was the official head of the UK delegation but retired from government service in 1995. 
goal posts. Some of them gave the impression that their conservation track record was so self-evident that this alone would win the day. They did not make an effective effort to win support from other African range states, who could be directly affected by the resumption of a legal trade, or from interested non-African countries. Nor was there sufficient consultation with experts beforehand that might have helped to improve the proposals and to influence governments indirectly. The logistics of the work of the Panels also proved more complicated than anticipated and hence the penetrating analysis provided by their reports came too late to be useful. They gave the fairest wind to the Zimbabwean and South African applications. Had these stood alone and benefited from persuasive advocacy, they might have made much more headway. Even if the Conference had not approved them, there could have been a friendly message to come back next time with improved proposals.

\section{Intersessional dialogue 1992-94}

Following a call from the president of the EC Environment Council at the Kyoto meeting for more dialogue between Conferences on controversial topics, the UK took the lead on elephants during its presidency later in 1992 and thereafter. This focused on an attempt to bring SACIM members into parley with range states in the other regions of Africa. A number of small subregional meetings led to the first representative African meeting in September 1994, organized by the UK for the EU, at Kasane, Botswana. Eighteen African range states drawn from all regions plus Japan, the US and three EU countries were represented. Preparatory papers by AfESG and CITES experts, the availability of simultaneous translation in French and English, and the involvement of co-chairs from each region in managing individual sessions all promoted a good discussion based on facts instead of the usual presentation of national positions, which characterizes so many formal intergovernmental meetings. It was a condition of get- ting delegations to Kasane that no positions would be taken up. As an exercise in bridgebuilding the meeting was a modest success. Field trips enabled West African officials to appreciate that Botswana has a very large elephant population, which is making life hard for villagers and farmers; Southern Africans began to take their counterparts in other regions more seriously; and SACIM outlined the possibility of co-operation on conservation, foreshadowing its change of name to the Southern African Convention for Wildlife Management. A French Government-financed meeting of francophone range states held semi-secretly just before Kasane in Central African Republic was unhelpful and doubtless intended to ensure that the countries concerned did not relax their opposition to the ban.

\section{Fort Lauderdale 1994}

The Kasane meeting, held only 2 months before the 9th Conference of the Parties to CITES at Fort Lauderdale, was too late to influence the formulation of any elephant proposals and, as it turned out, the outcome of those already tabled. Believing that a meeting in the USA would not be conducive to success, SACIM held its fire but South Africa submitted a downlisting application for trade in meat and hides, expressing its desire to trade in ivory (with CITES approval) in the future. When the latter indication provoked a storm of criticism from protectionist non-governmental organizations, the South Africans hesitated, were slow to drop the reference to ivory and failed to deliver the expected personal endorsement from President Mandela, even though the matter had been discussed in and endorsed by the South African Cabinet. Yet they had expert support for the view that the logistics of the international hide trade virtually rule out poaching as a serious possibility, while almost all elephant meat consumption is local. Moreover, having brought their elephant population of under 1000 in 1900 to some 10,000 in 1994, their conservation record in this century has been outstanding.

Although, as at Kyoto, South Africa with- 
drew before a vote was taken, the debate was far more constructive than in 1992 and support was voiced by a number of nonAfrican parties in addition to Japan and Switzerland, which had spoken in support at Kyoto. The Kasane meeting did not alter any formal African positions but it did lead to an agreement that the African region of CITES, through its representatives on the Standing Committee, would continue the dialogue before the next Conference, which was to be in Harare. The Sudanese downlisting application to dispose of that country's ivory stockpile failed to meet the various criteria in Resolution 7.9. The CITES Standing Committee was given the task of examining the implications of the ivory stock issue and revising the guidance to the Panel of Experts.

\section{The African dialogue}

As reported in Oryx (31, 9-10), another range state meeting took place in Dakar in November 1996. Organized and facilitated by IUCN with support from UNEP for CITES it was attended by 31 of the 37 range states. Discussion within the four elephant regions helped to confirm, clarify or present new data on populations, stocks, poaching and the illegal trade reviewed above. The plenary addressed a series of policy issues, the most productive element of which was an exposition by Botswana, Namibia and Zimbabwe of the downlisting applications, which were then in draft but have since been formally submitted for consideration by the Harare Conference. As at Kasane, no positions were taken on these proposals but there was more discussion and explanation. Those making the proposals seemed satisfied with the measured reaction and made it clear that they were very much in consultative mode, having taken the trouble to consult experts and officials from outside Southern Africa in advance, and inviting further comment before the formal submission date. All this was a welcome contrast to the suspicion and lack of openness that preceded Kyoto and should avoid the bitterness that characterized the debate at the 8th
Conference and contribute substantially to an informed discussion.

\section{The proposals to be considered at Harare}

South Africa has not submitted any elephant proposals to the Harare conference despite the generally favourable assessment of the hide trade given by TRAFFIC experts at Kasane and Dakar. The proposals from Botswana, Namibia and Zimbabwe, which all have healthy and well-managed elephant populations that have not been subject to largescale poaching, while separate and supported by very different sets of material, are similar in form. Each envisages direct exports of registered stocks of whole tusks originating in the exporting country to Japan only (not for any re-export) in single shipments in each of the two years, 1997-98 and 1998-99. The quotas planned for each of the 2 years are: Botswana, 12.68 tonnes; Zimbabwe, 10 tonnes; and Namibia, 6.9 tonnes. The proposals from Namibia and Zimbabwe also include noncommercial trade in live animals and hunting trophies, while Zimbabwe also includes trade in hides and non-commercial trade in leather articles and ivory carvings. The proposals contemplate a return to the following Conference before any further ivory trade is undertaken, allow for inspection by CITES and others of the shipments, and outline a procedure for the downlisting to be withdrawn before the next Conference if any abuses are identified. There are undertakings to use the revenue from sales exclusively for conservation and rural community development. Namibia has produced a number of leaflets and information sheets designed for the non-specialist audience and in one of these there is a welcome promise to co-operate with neighbouring countries in the monitoring of elephant population trends and the illegal trade.

At the time of writing (January 1997) the Panel of Experts' reports were not available, although the leak to The Times mentioned earlier indicated significant problems with internal control of the ivory stockpile in 
Zimbabwe and an apparent laxity of approach to major abuses by legally registered domestic dealers.

Subject to this important limitation it is appropriate to offer some preliminary comment on these proposals in order to encourage considered and rational debate before delegations arrive in Harare. There must be a welcome for the procedure that the three countries have adopted, consulting range states and others well beforehand and going out of their way to offer explanations. The biological case for treating these populations as non-endangered and therefore meriting Appendix II listing is overwhelming. Whatever views are held on a possible resumption of the ivory trade, Appendix I listing should not be retained just for symbolic purposes. There is also no doubt that the arrangements proposed for shipments of single cargoes of ivory, open to independent inspection, to Japan only, and for two years only, represent about as watertight an arrangement as it is possible to imagine, provided that the Japanese authorities can give assurances about the tracking of the ivory once it reaches Japan and before it is processed. Although Japan has introduced an internal ivory control law, delegates in Dakar who had a helpful exposition of it from a Japanese official did not seem to be convinced that the system would withstand independent scrutiny. Nevertheless, Namibia, with an elephant population approaching the capacity of the available habitat and a very large stockpile of ivory in relation to that population, appears to have as good a case for downlisting under the terms of Resolution 7.9 as can be made. Nor can there be any doubt that Botswana's elephant numbers are very high indeed and causing a whole range of problems for human communities as well as for plant diversity in parts of their range. Culling has long been put off for fear of international censure but may soon be inevitable, with a consequent escalation of the ivory stockpile. In the Experts' report for Kyoto there was criticism of Botswana's ivory management arrangements and it is not clear how far these problems have been dealt with. If they have,
Botswana's downlisting proposal also merits sympathetic consideration.

Zimbabwe's application presents more difficulty. Biologically the case for downlisting is incontestable, especially if it is recalled that at the turn of the century in this part of Africa the elephant population stood at 4000 and the human population was 5 per cent of its current level. In 1992 the Panel considered Zimbabwe's marking and management of its ivory stock as exemplary. It has also been well known that the Zimbabwean authorities have since 1989 been disposing of an average of 4-6 tonnes of ivory a year to local carvers and it has been assumed that some of this found its way into the tourist trinket market. Against this background a decision to release 10 tonnes in the first 9 months of 1996 is very hard to understand and if, as appears, the 'local carvers' have been found exporting semi-worked blocks to a range of countries under the guise of personal-use-artefacts, a good deal of tightening up is needed. In these circumstances Zimbabwe might attract more support if on this occasion it proposed a zero quota for ivory and sought only a trade in hides and live animals.

If more sympathy can be expected for the Southern African countries this time around in view of the trouble they have taken and the more limited nature of their proposals, there will still be concern about the possible knockon effects of any renewed legal trade. Enhanced monitoring of elephant populations and the illegal trade will be crucial if an assessment of the consequences of the proposed downlisting is to be made. Moreover, range states who are still anxious about the safety of their elephants may feel that they are being asked to take a risk without any compensating benefit. It would greatly assist the reception of these proposals, and not only in Africa, if a small but specific percentage of the net revenue from any ivory sales could be pledged to the international monitoring effort, which in this case must mean the work of TRAFFIC and AfESG, although much more than money is needed for effective monitoring. At the same time international donors should be urged to enhance their support, not least the Global 
Environment Facility. If Loxodonta africana is not a flagship species for conservation of global biodiversity it is hard to know what is.

\section{Beyond Harare}

If the proposals are accepted in whole or part, it will be vital for a parallel track of action to be developed alongside the monitoring of populations, poaching and the illegal trade. This should consist of serious study and debate on a range of policy issues. It must be recognized that the package under consideration is short-term and unlikely to deal with many of the issues affecting stockpiles or the position of other range states. One surprising piece of information to emerge at Dakar was a statement by the Japanese Government that their manufacturers hold 90 tonnes of tusks and 90 tonnes of semi-worked ivory, which was being processed in final form at the rate of 10 tonnes per year, only partly out of caution about the future of supplies. This rate of consumption can be compared with the total of 30 tonnes for each of 2 years, which the three downlisting countries propose to ship to Japan. This suggests that the proposals to be considered at Harare should be seen as strictly limited and not necessarily as the precursor of a post-1999 trade.

There needs to be an investigation of the non-Japanese markets for ivory to establish whether they are in principle open to control. It seems unlikely that satisfactory systems could be put in place by 1999 , even if the relevant authorities were ready to co-operate. If these markets were to become legal, another matter alluded to in Dakar is the possibility of adding value to raw ivory in Africa, by developing carving and marketing skills. The options for dealing with ivory stockpiles require much more examination; little progress was made on this aspect at Dakar. More work is needed on sustainable uses of elephants apart from ivory, because there is little experience or understanding of this in many range states. Finally, thought should be given to the development of an international mechanism, primarily African, to control any reopened market in African elephant ivory so that stocks in range states such as Sudan, who cannot meet the biological criteria for downlisting, could gradually be brought into the system and any benefits from a legal trade widely shared. This would, of course, require changes in the CITES arrangements and at the moment this seems to be a remote prospect. Nevertheless, some imaginitive thinking, as well as good will and commitment, will be needed quite soon if a viable way is to be found for people and elephants to co-exist in the endlessly challenging continent of Africa.

\section{References}

Cobb, S. (ed.) 1989. The Ivory Trade and the Future of the African Elephant. Ivory Trade Review Group, Oxford.

Douglas-Hamilton, I., Michelmore, F. and Inamdar, A. 1992. African Elephant Database. United Nations Environment Programme, Nairobi, Kenya.

Dublin, H.T., Milliken, T. and Barnes, R.F.W. 1995. Four Years after the CITES Ban: Illegal Killing of Elephants, Ivory Trade and Stockpiles. A report of the IUCN/SSC African Elephant Specialist Group, Nairobi.

IUCN/SSC. 1996. African Elephant Specialist Group. Conservation of the African Elephant: Issues and Actions. A report to the IUCN/CITES Meeting Promoting Dialogue between African Countries on the Conservation of the African Elephant. 11-16 November, 1996, Dakar, Senegal.

Milliken, T. 1997 (in press). The status of ivory stocks in Africa 1990-1996. TRAFFIC Bulletin, 16 (3).

Milliken, T. and Sangalakula, L. 1996. TRAFFIC East/Southern Africa. The Illegal Ivory Trade since the CITES Ban: Using Law Enforcement Data to Assess Trends. A report to the IUCN/CITES Meeting Promoting Dialogue between African Countries on the Conservation of the African Elephant. 11-16 November 1996, Dakar, Senegal.

Said, M.Y., Chunge, R.N. Craig, G.C., Thouless, C.R. Barnes, R.F.W. and Dublin, H.T. 1995. African Elephant Database. IUCN, Gland, Switzerland.

Robin Sharp, 30 Windermere Avenue, London NW6 6LN, UK. 